\title{
The Effectiveness of Social Skills Training Groups for Individuals with Autism Spectrum Disorder
}

\author{
Matthew Hotton ${ }^{1} \cdot$ Sarah Coles $^{2}$ \\ Received: 22 June 2015 / Accepted: 24 November 2015 /Published online: 17 December 2015 \\ (C) The Author(s) 2015. This article is published with open access at Springerlink.com
}

\begin{abstract}
Autism spectrum disorder (ASD) is characterised by social difficulties that can have a negative impact on an individual's psychological and social wellbeing. To date, reviews of social skills training groups have mainly focussed on children, rather than adolescents and adults. This review aimed to critically evaluate studies published in the past 20 years that had used group-based social skills training to improve the social skills of adults and/or adolescents with ASD. Thirteen studies were identified, and group-based social skills training was generally effective at improving social skills, with some studies observing transfer effects to improvements in wider psychological wellbeing. Future research should focus on comparing different social skills training protocols in real-world clinical settings.
\end{abstract}

Keywords Autism spectrum disorder · Social skills training · Asperger syndrome $\cdot$ Social interaction $\cdot$ Social communication $\cdot$ Review

Matthew Hotton

Matthew.Hotton@hmc.ox.ac.uk

1 Isis Education Centre, Warneford Hospital, University of Oxford, Oxford Institute of Clinical Psychology Training, Oxford, UK

2 Southern Health NHS Foundation Trust, Abbey House, Abingdon, UK

\section{Introduction}

\section{The Nature of Social Difficulties in Autism Spectrum Disorder}

The Diagnostic and Statistical Manual of Mental Disorders, Fifth Edition (DSM-5) proposes 'impaired social interaction and communication' as key criteria for the diagnosis of autism spectrum disorder (ASD; American Psychiatric Association 2013). This reflects the combined nature of social interaction and communication difficulties in ASD. Social skills can be thought of as the behaviours involved in initiating and maintaining interpersonal relationships (Elliot and Gresham 1987) and are linked to peer-acceptance, psychological wellbeing and academic achievement (Hartup 1989). There is variation in the degree to which individuals with ASD are motivated to interact with peers, with some individuals desiring social interaction, but lacking the skills to negotiate social situations, while others show minimal interest in social interactions (Reichow et al. 2012).

The social interaction and communication difficulties of individuals with ASD span a range of skills (Weiss and Harris 2001). Research indicates difficulties with recognising and discriminating facial emotional expressions (Harms et al. 2010), using eye gaze to scan social information (Pelphrey et al. 2002) and engaging in joint attention (Dawson et al. 2004). These skills are considered important for the interpretation of the intentions of others, putting individuals with ASD at a disadvantage during social interactions (Leppänen and Nelson 2006). People with ASD can also have difficulties identifying appropriate greetings (Reichow and Sabornie 2009) and understanding humour (Samson and Hegenloh 2010). Social difficulties predict a lower number of peer relationships and reduced participation in recreational 
activities (Orsmond et al. 2004), as well as reduced ability to form romantic relationships (Stokes et al. 2007), factors known to lead to a significant reduction in psychological wellbeing (Whitehouse et al. 2009).

There are multiple theories which conceptualise the social difficulties of people with ASD and although a comprehensive discussion of these is beyond the scope of this review, some will be briefly described. One such theory is impairments in theory of mind (ToM; Vrticka et al. 2013), defined as the ability to conceive the mental states of others (Baron-Cohen et al. 1985), can lead individuals with ASD to initiate fewer social interactions for fear of 'getting it wrong', thus perpetuating their social difficulties (Shtayermman 2007). Cognitive neuroscientists claim a link between mirror neuron deficiency and ASD (Dapretto et al. 2006; Perkins et al. 2010). Furthermore, anatomical differences have been found in the mirror neuron related brain areas in adults with ASD, compared with controls. Cortical areas were thinner, and the degree of thinning was correlated with ASD symptom severity, a correlation mostly restricted to these brain regions (Hadjikhani et al. 2006). Based on these results, some researchers claim that ASD is caused by impairments in the mirror neuron system, leading to disabilities in social skills, imitation, empathy and theory of mind. However, other researchers argue that this theory alone cannot account for these deficits, links are tentative and that further research in this area is required (Heyes 2010). Another prominent theory of ASD is that there are underlying deficits in executive functions (Russell 1997). Executive dysfunction, for example, difficulties in planning, flexibility, and organising, has been linked with the theory of mind difficulties associated with impaired social behaviour (Fisher and Happe 2005). Likewise, Weak Central Coherence, a processing bias for local rather than global information, has been posited as a further factor that can contribute to social difficulties (Happé and Frith 2006). For example, Happé and Frith argued that weak central coherence may lead to poor processing of facial emotion or the interpretation of social behaviour in a specific context. A more recent theory accounting for the social impairments of people with ASD is the social motivation theory of Chevallier et al. (2012), which argues that the reduced social motivation of individuals with ASD can lead to their social difficulties.

\section{The Implications of Poor Social Skills for Psychological Wellbeing}

Although a comprehensive discussion of the psychiatric implications of poor social skills is beyond the scope of this review, it is notable that poor social skills appear to contribute to reduced psychological wellbeing for individuals with ASD. Individuals with ASD often display higher levels of depression than the general population (Stewart et al. 2006). For example, Lugnegard et al. (2011) study reported that $70 \%$ of adults with ASD met the criteria for having experienced at least on episode of major depression, as categorised by the DSM-4 (American Psychiatric Association 2000). It is hypothesised that this increased prevalence is partly related to difficulties with social interaction leading to feelings of incompetence and low self-esteem (Hillier et al. 2011). Sterling et al. (2008) purport that increased prevalence of depression in adults with ASD who are 'higher functioning' may be as a result of insight into their own social difficulties. This is because individuals who perceive themselves as being socially isolated experience higher levels of loneliness and depression (Cacioppo and Hawkley 2009). Individuals with ASD also experience high rates of anxiety, particularly social anxiety (Bellini 2004), with an estimated $50 \%$ of adults with ASD experiencing an anxiety disorder (Lugnegard et al. 2011). Heightened levels of anxiety and physiological arousal make social interactions more overwhelming and leads to social withdrawal. This restricts an individual's opportunity to develop social skills and can produce more social faux pas and consequently a higher number of negative social interactions and embarrassment (Bellini 2006). Therefore, not only does increased anxiety lead to social difficulties, but these difficulties can often lead to greater anxiety, indicating a bidirectional relationship (White et al. 2014). The significant mental health consequences of social skills difficulties highlights the importance of improving social skills with targeted interventions as this may in turn lead to improvements in mental health.

Despite the discussion of the social difficulties of individuals with ASD, it is important to consider an alternative representation: that of ASD as a difference. It has been argued that individuals with ASD only become socially 'disabled' due to a lack of accommodation of this difference by society (Brownlow 2010). SST groups may perpetuate this lack of accommodation, training people with ASD on how to appear 'Neurotypical', rather than acknowledging neurodiversity and the strengths of individuals with ASD.

\section{Social Skills Training Groups}

The implications of poor social skills demonstrated by individuals with ASD highlight the importance of supporting individuals to develop their social interaction and communication abilities. One of the most commonly used interventions that aims to achieve this end are Social Skills Training (SST) groups. Different groups follow different protocols, but generally contain two to six participants, are led by multiple therapists and run for around 12 weeks (Reichow et al. 2012). The aim of such groups is to teach specific skills within a setting where they can be immediately rehearsed and reinforced, thus providing a positive social experience. 


\section{Review Objectives}

Reviews of the SST literature to date have only explored research focusing on children and adolescents (e.g. Rao et al. 2008; Reichow et al. 2012; Miller et al. 2014). These reviews have shown how SST groups may improve the social skills of some children and adolescents with ASD, but highlight the need for further research measuring broader outcomes, such as quality of life. However, people with ASD do not grow out of their social difficulties and they persist into adulthood, along with the associated psychosocial consequences discussed above. This makes it of great importance to identify any interventions which may support adults to develop their social skills. This review therefore aims to identify and critically evaluate studies that have investigated the effectiveness of SST groups at improving social interaction and communication in adolescents and adults with ASD.

\section{Methods}

\section{Scope of Review and Inclusion Criteria}

This review considered all research published in peerreviewed journals focusing on group interventions for improving social skills and/or peer relationships in adolescents and adults with a diagnosis of an ASD from 1994 to 2014. A variety of study designs were included, such as: randomised controlled trials (RCTs), single-case multiple baseline designs and quasi-experimental designs.

\section{Search Strategy}

A literature search was carried out using online databases (PsychINFO, EMBASE, Medline) through an National Health Service (NHS) Healthcare search engine. The search strategy and search terms are shown in Appendix 1.

\section{Exclusion Criteria}

Studies were excluded if they:

- Did not include individuals with an ASD

- Recruited participants with a mean age of younger than 13 years of age

- Were not written in English

- Were not published in a peer-reviewed journal

- Did not include information about a relevant outcome (e.g. social skills or peer relationships)

- Were not empirical research (e.g. they were reviews or commentaries)

- Were not a group-based SST intervention

\section{Study Selection}

The eligibility of studies was determined by an initial screening by the first author based on the titles and abstracts of articles. This was followed by the full text of the remaining shortlist being screened in agreement with inclusion and exclusion criteria. Reference lists of included studies were also read to indicate other applicable studies. The second author double-checked included studies to ensure they met inclusion criteria.

\section{Data Items}

Information was extracted from each study on (1) characteristics of participants (including age, gender and diagnosis); (2) study design (including sample sizes and number of groups); (3) type of SST intervention; (4) type of outcome measures used; (5) type of control group (if applicable); and (6) training effects.

\section{Results}

\section{Study Selection}

The search identified 230 studies. The titles and abstracts of these studies were reviewed, and 29 studies were identified to be suitable for this review, with the remaining 201 studies clearly not meeting criteria. Upon further inspection of the full text of the remaining 29 studies, 16 of these studies did not fulfil criteria, leaving 13 studies to meet the inclusion criteria for the current review. The phases of selection are shown in Fig. 1 in line with the Preferred Reporting Items for Systematic Reviews and Meta-analyses (PRISMA) guidelines (Liberati et al. 2009).

\section{Study Characteristics}

Four RCTs (Gantman et al. 2012; Laugeson et al. 2009; Schohl et al. 2014; Yoo et al. 2014), three quasi-experimental pre-post designs with a control group (Laugeson et al. 2012; Ozonoff and Miller 1995; Turner-Brown et al. 2008), four quasiexperimental pre-post designs without a control group (Hillier et al. 2007, 2011; Liu et al. 2013; Tse et al. 2007), one randomised complete block design study (Mandelberg et al. 2014) and one single-case multiple baseline study (Mitchel et al. 2010) were identified.

The included studies came from only four countries (USA, 9; Canada, 2; Hong Kong, 1; South Korea, 1), with five of the studies involving the same research group at the University of California, Los Angeles (UCLA; Table 1). Six different SST interventions were investigated; however, no study compared 
Fig. 1 Study selection process

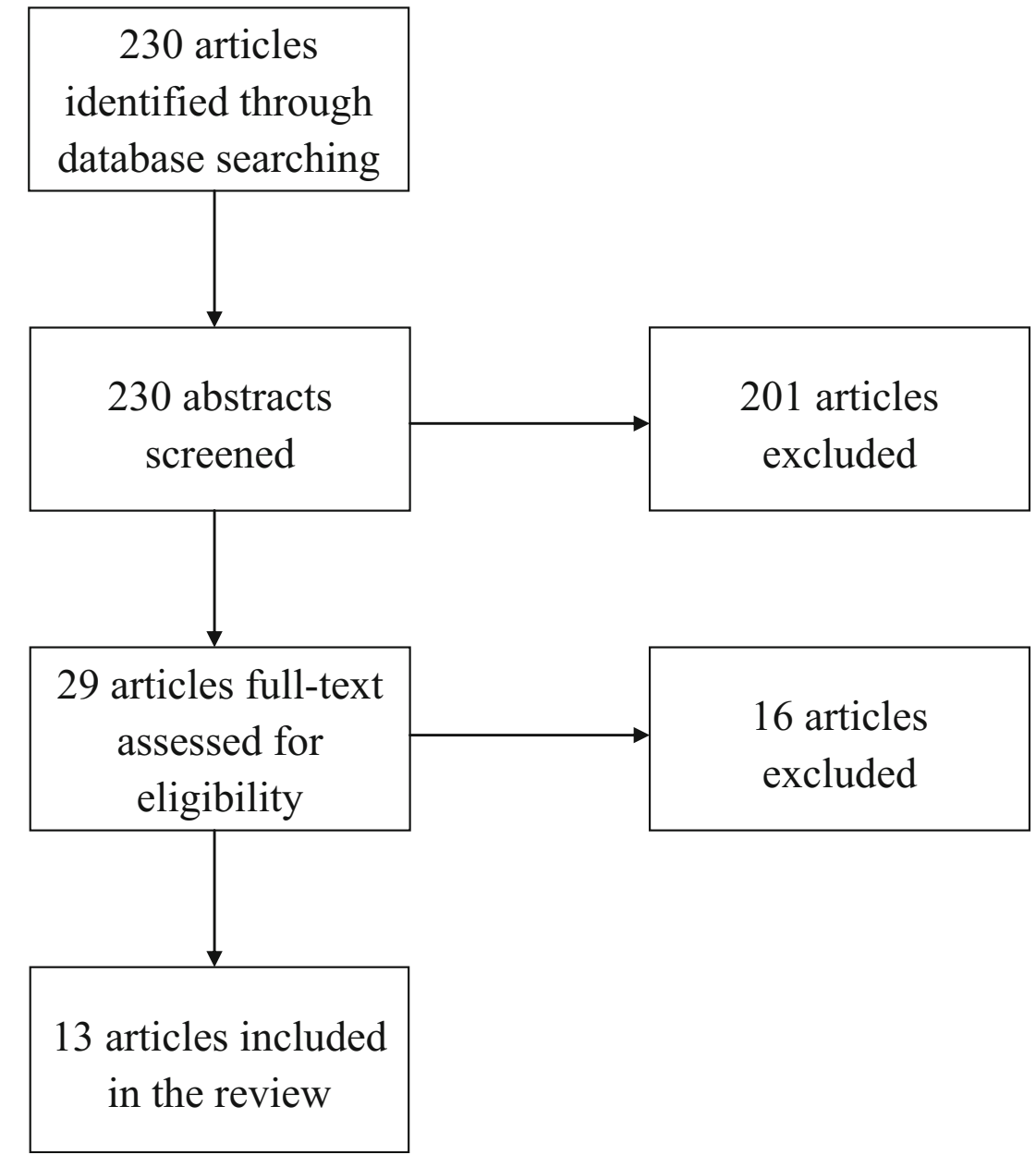

different interventions against each other. The majority of studies only recruited participants without an intellectual disability (defined as an IQ below 70, as well as impairment in adaptive and social functioning, present before the age of 18; Department of Health 2001); however, there was heterogeneity with regards to the autism diagnoses of included participants, as well as how they were described. Different studies use different terminology; for example, high-functioning autism and Asperger syndrome have both been used historically to describe adults with ASD who do not have an intellectual disability.

\section{Evaluation by SST Type}

Programme for the Education and Enrichment of Relational Skills

The UCLA Programme for the Education and Enrichment of Relational Skills (PEERS) aims to address a range of social skills. PEERS involves 12-14 weekly sessions, with each session lasting $90 \mathrm{~min}$ and typically includes a parent or caregiver. Four studies evaluating PEERS used an RCT design (Laugeson et al. 2009; Gantman et al. 2012; Schohl et al. 2014; Yoo et al. 2014), and each of these included a wait-list control group. One study employed a quasi-experimental pre-post design in which participants were not randomly assigned to their conditions and there was no control group (Laugeson et al. 2012). This study followed a similar protocol to Laugeson et al. (2009) but with two additional sessions and a follow-up period, something not present in the other studies. A further study by Mandelberg et al. (2014) was described as a randomised complete block design. They assessed adolescents with ASD at three time points: prePEERS intervention; post-intervention and 1- to 5-year follow-up. Thus, participants can be considered as 'blocks' and the different time points as 'treatments'.

The protocol was described thoroughly in all six studies. PEERS was translated and modified for a Korean population in the Yoo et al. study. Only the Schohl et al. study was independent of UCLA, which reduces the risk of investigator bias compared with the other studies. One study (Gantman et al. 2012) evaluated PEERS in adults between the ages of 18 to 23 years, 


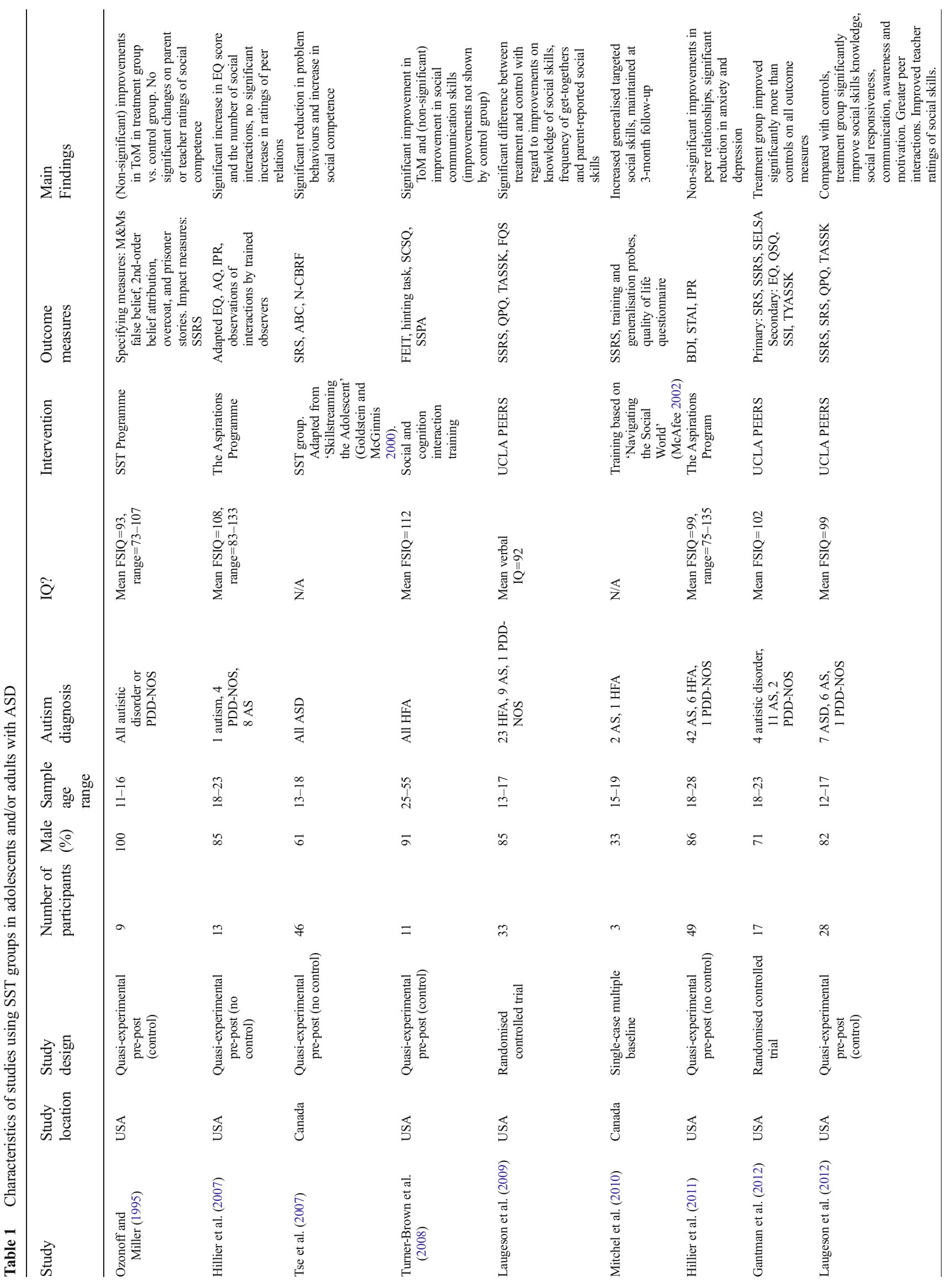




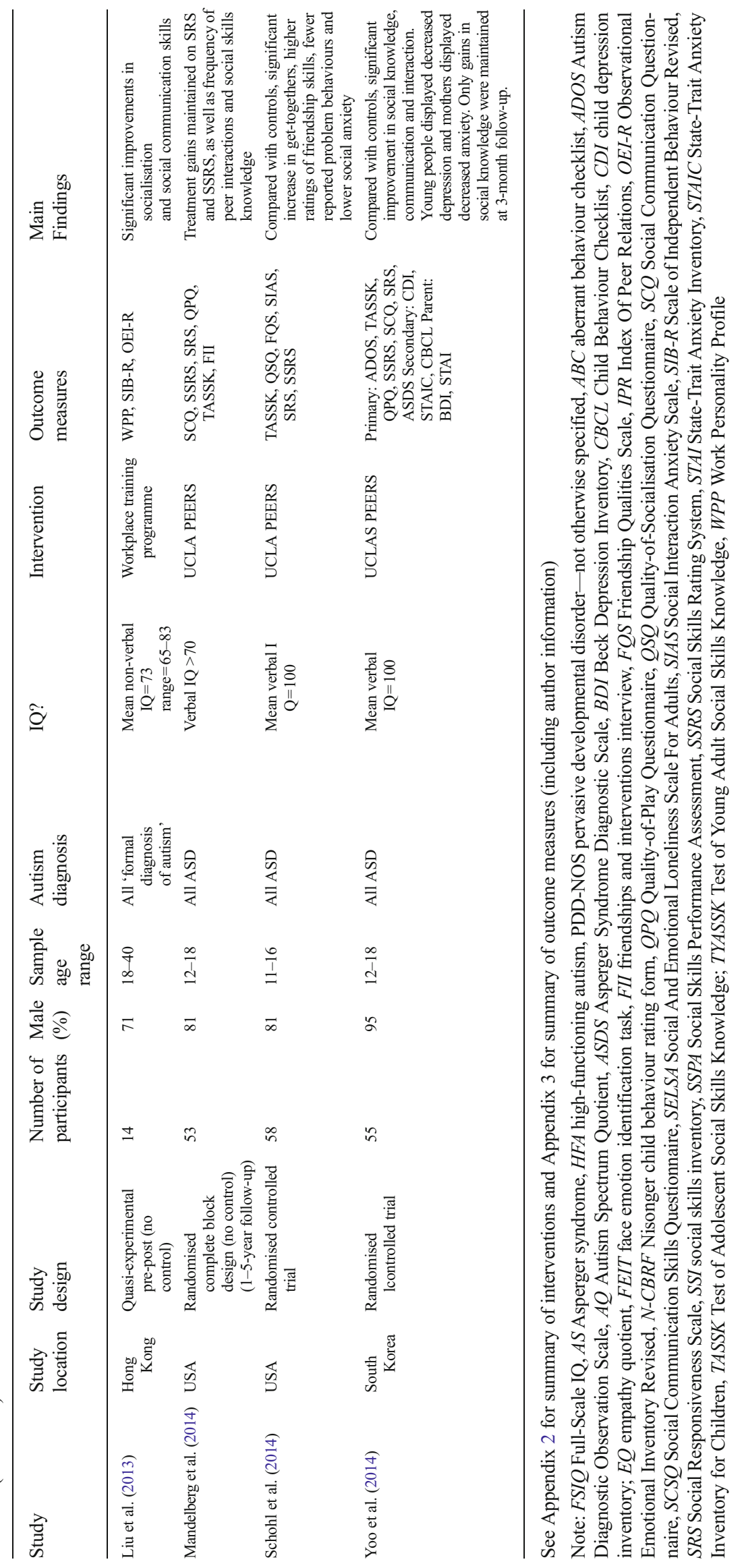


while the other five studies investigated adolescents between the ages of 11 to 18 years.

The six studies used a variety of outcome measures. All six studies used the Social Skills Rating System to assess cooperation, assertion, self-control and social responsibility (SSRS; Gresham and Elliott 1990). Gresham and Elliot found the SSRS to have an internal consistency of 0.75 , test-retest reliability for teacher ratings between 0.84 and 0.93 and test-retest reliability for parent ratings between 0.65 and 0.80 . However, this measure is yet to be validated in an ASD population. The SSRS was completed by parents, caregivers and/or teachers apart from in the study by Yoo et al. (2014) where it was answered by the participants, with no significant condition-time interaction being observed. Indeed, this was the only study to fail to observe significant improvements by participants on the SSRS. This was attributed to the participants' limited insight regarding their difficulties and differences between participants' and parents' metacognitive abilities with regards to social behaviour, rather than the group not being effective. This raises questions regarding whose idea it was to attend the group and what expectations parents and participants had for taking part in the group. This is not reported on in the study.

The administration of the Social Responsiveness Scale (SRS; Constantino 2005) by all studies apart from Laugeson et al. (2009) allowed for the assessment of change through the use of an ASD-specific measure of social skills, with Yoo et al. (2014) being the only study not to observe significant change on this measure. A further assessment of changes in ASD-related symptoms was administered by Yoo et al., who observed significant improvements in social interaction and communication. Gains in both the SSRS and SRS were maintained at follow-up in the studies of Laugeson et al. (2012) and Mandelberg et al. (2014).

While Laugeson et al. (2009) and Schohl et al. (2014) both assessed friendship quality, only Laugeson et al. found significant time-condition interaction, which was in fact due to a reduction of the controls' scores. Mandelberg et al. (2014) also assessed post-intervention improvements in friendship and observed an increase in the number of get-togethers organised with peers after PEERS, and this was maintained at follow-up.

In terms of mental health-related outcomes, Yoo et al. (2014) investigated the effect of the intervention on anxiety and depression, for both the young people and their parents. They found reductions in maternal anxiety and the depressive symptoms of participants. Gantman et al. (2012) assessed loneliness, observing a significant improvement.

Improvements in social skills knowledge, as measured by the Test of Adolescent Social Skills Knowledge
(TASSK; Laugeson and Frankel 2006) or the Test of Young Adult Social Skills Knowledge (TYASSK; Gantman et al. 2012), were found in all six studies. This suggests that PEERS is successful in improving the social skills knowledge of people with ASD.

\section{Critique}

All four RCT studies can be thought of as randomised wait-list controlled designs, as no studies included a notreatment control. This has the advantage of all participants receiving treatment; however individuals in the treatment group may have had higher expectations of improvement. By not including a third arm to their designs involving a separate intervention, these studies were unable to evaluate whether treatment effects were specific to PEERS. There were no significant differences in participant demographics or baseline social skills between groups at baseline in all studies which included a control group.

By not randomising participants, Laugeson et al. (2012) and Mandelberg et al. (2014) increased the risk of selection bias; however by employing a control group Laugeson et al. were able to reduce the risk of bias due to non-intervention-related events or maturation. The study of Mandelberg et al. (2014) is perhaps more appropriately thought of as a quasi-experimental design without a control group and as such is susceptible to multiple sources of bias, such as that caused by previous testing, or natural improvements over time. However, as participants had originally been randomised to the treatment group, this reduced the risk of selection bias.

Across studies, many of the measures were administered to parents and/or caregivers, who were not blind to the treatment status of the individual with ASD. This introduced risk of detection bias, especially since parents were involved in the interventions. Yoo et al. (2014), Laugeson et al. (2012) and Mandelberg et al. (2014) were the only studies to have a follow-up period, which allowed for observation of the development of skills and whether post-intervention improvements were sustained or generalizable outside of the group. All six studies had similar inclusion and exclusion criteria, including the exclusion of people with an intellectual disability, meaning that findings may not be generalizable to all individuals with ASD.

The use of behavioural, in vivo measures may have improved the ecological and construct validity of these studies, something which was acknowledged by Gantman et al. (2012) and Schohl et al. (2014) and addressed by Yoo et al. (2014) who used the Autism 
Diagnostic Observation Schedule (Lord et al. 2008) to observe social interaction, communication and play.

\section{Aspirations Programme}

Two studies employed a quasi-experimental design without a control group to evaluate the Aspirations programme for adults with ASD (Hillier et al. 2007; Hillier et al. 2011). This programme runs for $1 \mathrm{~h} /$ week, for 8 weeks, has a discussion-based format and was designed to help adolescents or young adults with ASD to develop social and vocational skills. Topics covered included: social communication, relationships, independence and employment.

Participants had an average age of 19 years in the study of Hillier et al. (2007) and 21 years in the study of Hillier et al. (2011). Participants completed a variety of outcome measure pre-and-post the Aspirations programme. Both studies used the Index of Peer Relations to assess attitudes and feelings towards peers, and neither found peer relations to improve. In addition, Hillier et al. (2007) focused on constructs related to ASD, administering the Autism Spectrum Quotient (AQ; Baron-Cohen et al. 2001) and the Empathy Quotient (EQ; Baron-Cohen and Wheelwright 2004), but only found significant improvement on the EQ. Hillier et al. (2011) observed the effects of training on anxiety and depression and found significant, but small, self-reported improvements for both of these on the Beck Depression Inventory (Beck et al. 1996) and State-Trait Anxiety inventory (Spielberger et al. 1983).

\section{Critique}

Neither study included a control group or randomised participants to their conditions. Participants were generally self-selecting and therefore perhaps more motivated to demonstrate a positive change, especially since participants had to pay to participate in the programme. Since neither study included a follow-up period, it was not possible to assess whether positive effects were sustained. As described above, since all the measures used in these studies were self-report. The inclusion of more objective measures of peer relations or ASD symptoms may have indicated whether improvements in participants' awareness of other people's perspectives, thoughts and feelings, as indicated by improvements in the EQ, led to behavioural change.

\section{Group Skills Training}

Mitchel et al. (2010) conducted a single-case multiple baseline design, and also measured social skills and quality of life pre-intervention, post-intervention and at 3-month follow-up. Three participants with a diagnosis of Asperger syndrome or high-functioning autism, labels historically used to described individuals with ASD without an intellectual disability, aged between 15 and 19 years took part in the 12-week intervention, which was adapted from 'Navigating the Social World' by McAfee (2002).

Unlike the group designs discussed thus far, this study offers an idiographic perspective of SST. The authors used participants' lowest baseline scores on the SSRS to choose three areas to target for training: introducing self to others; joining in activities and problemsolving (Mitchel et al. 2010) and developed appropriate training (in a setting with trainers, e.g. role plays) and generalisation (in a setting without trainers, e.g. not in the training room) probes to measure these target behaviours. These probes were observations of target behaviours that were identified and rated by a facilitator. A video coder, blind to the study purpose, rated $20 \%$ of the probes and high inter-observer agreements for training $(89 \%)$ and generalisation $(87 \%)$ probes were reported.

Social skills and quality of life improved for all participants and improvements were maintained at 3-month follow-up. The intervention was generally associated with increased generalisation of targeted social skills.

\section{Critique}

One of the strengths of single-case designs is to monitor baselines; however, baselines were observed as little as once for some target behaviours before training was delivered and scores were highly variable when more baseline observations occurred. Single-case designs often have limited generalisability. However, the authors attempted to address these issues by testing three participants, thus identifying sources of variability. However, Mitchel et al. (2010) acknowledged that their design was weakened because they did not have the time to ensure previously trained skills had improved before training a new skill. Furthermore, there is the important consideration that target behaviours were identified based on SSRS scores, rather than participant choice, which may have reduce participants' motivation to improve those behaviours.

\section{Social Skills Training Programme}

Ozonoff and Miller (1995) evaluated a Social Skills Training Programme consisting of 14 weekly 90-min sessions. The first 7 weeks focussed on conversational and interactional skills, with the second 7 weeks 
focussing on ToM skills. They employed a pre-postdesign in which participants were not randomly assigned to their conditions, placing participants in a treatment or no-treatment control group based on practical constraints which were not specified.

Ozonoff and Miller (1995) administered multiple measures designed to assess ToM; however, only found marginally significant improvements when the treatment and control groups were compared. No significant main effects or interactions were observed on assessments of social functioning, as measured by the SSRS.

\section{Critique}

By not randomising participants, this study was at increased risk of selection bias. However, by employing a control group, there was reduced risk of bias due to non-intervention-related events or maturation. The training methods provided by the authors used examples very similar to the false belief tasks used as outcome measures and the authors acknowledged that their intervention may have only served to teach participants how to pass these tasks, rather than actually improve ToM.

\section{Social Skills Training Group}

Tse et al. (2007) evaluated a Social Skills Training Group which consisted of 60- to 90-min sessions once a week for 12 weeks. The group consisted of a mixture of psychoeducation and experiential exercises and included both role-play and didactic elements. The content of the group was based on 'Skillstreaming the Adolescent' by Goldstein and McGinnis (2000). The design of the study was quasi-experimental, without a control group and participants had a mean age of 14.60 years. Participants' parents completed three questionnaires pre- and post-group: the Social Responsiveness Scale (Constantino 2005), the Aberrant Behaviour Checklist (ABC; Aman et al. 1985) and the Nisonger Child Behaviour Rating Form (N-CBRF-PS; Aman et al. 1996). The authors observed small but significant improvements in social competence, as measured by the SRS and N-CBRF-PS. Effect sizes were greater for the significant reduction in problem behaviours, as measured by the $\mathrm{ABC}$.

\section{Critique}

As with other studies with a similar design (e.g. Liu et al. 2013; Hillier et al. 2007; Hillier et al. 2011), the lack of control group reduced the authors ability to identify whether changes in social skills were greater than they would have been had participants not received an intervention or whether improvements were simply due to group participation. By not randomising, there was increased risk of selection bias.

As a service-oriented study, it had increased external and ecological validity and offered insight into how interventions apply to clinical practice. However, without a follow-up period, it was not possible to assess whether positive effects were sustained.

\section{Social Cognition and Interaction Training for Adults}

Turner-Brown et al. (2008) evaluated a Social Cognition and Interaction Training for Adults (SCIT-A) programme, which consists of three core components: emotion training; figuring out situations and integration of principles. The programme consisted of 18 weekly sessions, lasting $50 \mathrm{~min}$ each and participants were 25 to 55 years of age. This study had a quasi-experimental pre-post-design with a control group which involved treatment as usual. Authors had attempted to randomise participants; however, they were not able to carry out a true RCT as two participants declined the SCIT-A programme and therefore were assigned to the treatment as usual control group. This control group continued to receive interventions, such as medication and individual therapy. Unfortunately, further information about these interventions are not discussed in this article. A variety of questionnaire and behavioural measures were used to assess improvements as a result of the group. Participants who completed SCIT-A showed significant improvements in ToM but not in the identification of facial emotions, compared with controls. No significant improvements were observed for social functioning. Importantly, five out of six of the participants rated the group as either 'useful' or 'very useful'.

\section{Critique}

This study's internal validity was reduced by all the factors discussed above that are associated with a lack of true randomisation. This study demonstrated increased risk of a selection-maturation interaction bias due to significant age differences at baseline. A potential reason why Turner-Brown et al. (2008) did not observe improvements in outcomes was that they did not administer measures which were designed for people with ASD and therefore they may not have been sensitive to change. The use of behavioural measures of social functioning during role-play increased the ecological and external validity of this study. A further benefit of this study was that it directly assessed the acceptability of the group for participants, something lacking from the majority of other studies. 


\section{Workplace Training Programme}

Liu et al. (2013) used a quasi-experimental pre-postdesign without a control group to evaluate a workplace training programme which lasted for $6 \mathrm{~h}$ a day, 5 days a week, for 6 months. This made it the most rigorous SST programme and most demanding of participant time. The programme had a focus on social communication and emotions, as well as psychoeducation about workplace principles. Participants had ASD and a mild to moderate intellectual disability and had a mean age of 24.60 years. The intervention led to significant improvements in some workplace social behaviour: appearance, self-control and level of supervision. There were also significant improvements in social communication skills and emotional control.

\section{Critique}

By not including a control group or randomisation, this study was at risk to many sources of bias. Like the study of Tse et al. (2007), this was a service-oriented study with increased external and ecological validity. However, the lack of follow-up means that longer term or maintenance effects of the intervention cannot be assessed.

\section{Discussion}

This review highlights the promising potential of SST groups as being an effective intervention for improving the social skills of adolescents and adults with ASD. Much research to date has focussed on evaluating UCLA PEERS. The quality of these studies was generally higher than studies evaluating other interventions and majority of PEERS studies reviewed observed improvements in social interaction, social skills knowledge and friendship quality. Furthermore, Yoo et al. (2014) and Gantman et al. (2012) found significant improvements in mental health outcomes, suggesting that the effects of SST transferred to wider psychological factors. This highlights the important relationship between social skills and mental health (White et al. 2014), and the valuable role that SST can play in improving these factors.

Positive mental health outcomes were also found by Hillier et al. (2007) and Hillier et al. (2011) following the Aspirations programme for adults with ASD; however, participants did not feel that their peer relations had improved as a result of the group. Future evaluations of the Aspirations programme may benefit from more direct observations of changes in social skills.
Mitchel et al. (2010) found significant improvements in social skills and quality of life following their Social Skills Training. Although adults with ASD rated SCITA (Turner-Brown et al. 2008) as being useful, significant improvements in social functioning were not observed. Similar social functioning outcomes were observed for the programme of Ozonoff and Miller (1995), and only small improvements in social competence after attending a Social Skills Training Group were found by Tse et al. (2007). Taken together, these findings indicate that SST group interventions vary with regards to their effectiveness at improving the social skills of adults and adolescents with ASD. The most compelling evidence for SST comes from the PEERS literature, which also suggests that improvements in social skills can lead to improvements in wider psychosocial factors, such as friendships and mental health.

To date, only one study (Liu et al. 2013) exclusively investigated training of individuals with an intellectual disability. Interestingly, Liu et al.'s intervention was by far the most time-consuming, lasting $30 \mathrm{~h}$ a week for 6 months. Although Liu et al. observed many positive social, emotional and workplace-related outcomes, it may be beneficial for future research to examine whether shorter groups are equally effective for a population with an intellectual disability, as a shorter SST group may provide a more cost-effective intervention.

The majority of studies included in this review were not truly experimental and most had small sample sizes and this limits our ability to draw conclusions from them. It is also important to consider what is indicated by a lack of significant improvement on outcome measures. Interventions may have helped participants to develop insight into their own social difficulties and therefore a lack of improvement may reflect greater social understanding (Hillier et al. 2011; Posavac and Carey 1992). It is also important to note that the included studies rarely made reference to participants' views regarding social difficulties or whether the goals of the group for participants matched the goals of facilitators, researchers or family members. An unfortunate consequence of this was that SST groups included in this review generally failed to customise their content to provide individualised, person-centred interventions based on participants' goals.

There is data from research to suggest that there are common factors that in some part determine the effectiveness of any intervention: client hope, expectations, therapist allegiance and relationship between client and therapist (Wampold and Budge 2012; Blow et al. 2007). Little information was provided in the reviewed studies about the quality of the relationship between group 
members and facilitators, and it is unclear how important these factors might have been in producing positive outcomes for people with ASD.

\section{Implications for Clinical Practice and Future Research}

Studies varied in the level of detail they provided about their curricula, with manualised approaches such as PEERS and SCIT-A providing more detailed descriptions, increasing their usability in clinical settings. Only a small number of studies investigated the effectiveness of SST groups in a community setting indicating a need for larger studies focussing on this. This review is also perhaps a timely reminder of the need of more research investigating SST groups for individuals with ASD and an intellectual disability, so that services can best support this population.

The effectiveness of different SST interventions should be compared in the future using RCTs. Furthermore, stepped treatments and experimental therapeutics, whereby mediating mechanisms are assessed, may help determine the 'active ingredient' involved in any improvements. The 13 included studies implemented 37 different outcome measures, which reduces our ability to compare different interventions and develop guidelines of what should be included in curricula. Research should be consistent in terms of outcome measures used, while at the same time assessing a wide range of outcomes beyond social competence. Research could also move away from utilising self-report measures or ensure that measures are designed for people with ASD, due to these measures increased sensitivity and this population's difficulties accessing their own mental states (Baron-Cohen 1989). This highlights the need for triangulation of data, using multiple methods of evaluation, such as objective behavioural measures, alongside self-report measure and assessments of participants' experiences of SST groups. Longitudinal studies will provide greater knowledge of the time-course and sustainability of intervention-related gains, as well as the individual differences involved in successful training, and the potential to generalise what was learnt in the group to real life situations.

\section{Ethical Considerations}

Information about participant satisfaction was only collected in three studies (Hillier et al. 2007; Tse et al. 2007; Turner-Brown et al. 2008) and only five studies clearly indicated that they had obtained consent from the participant and/or a parent (Hillier et al. 2007, 2011; Liu et al. 2013; Mandelberg et al. 2014; Yoo et al. 2014). It is important this information is indicated, given the vulnerability of many people with ASD.

\section{Limitations of the Current Review}

The current review was limited by only including group interventions. Many other interventions, such as intensive interaction, individual SST and Cognitive Behavioural Therapy (e.g. Sze and Wood 2007) have been designed for this population and future reviews could seek to compare different modalities of interventions. A further limitation is the low number of studies which included participants with an intellectual disability. By reviewing adolescents and adults together, this review may have obscured important differences between interventions for these two age groups. Once sufficient research has been published, future articles may benefit from reviewing SST interventions for adults alone.

\section{Compliance with Ethical Standards}

Conflict of Interest The authors declare that they have no conflict of interest

\section{Appendix 1-Search Strategy}

1. EMBASE, MEDLINE, PsycINFO and autis*.ti, 39,491 results.

2. EMBASE, MEDLINE, PsycINFO and PDD.ti, 239 results.

3. EMBASE, MEDLINE, PsycINFO and 'pervasive developmental disorder*'.ti, 1500 results.

4. EMBASE, MEDLINE, PsycINFO and asperger*.ti, 2725 results.

5. EMBASE, MEDLINE, PsycINFO and kanner.ti, 49 results.

6. EMBASE, MEDLINE, PsycINFO and 1 OR 2 OR 3 OR 4 OR 5, 42,835 results.

7. EMBASE, MEDLINE, and PsycINFO (social AND (skills OR competence OR engagement OR relationship* OR interaction*)).ti, 23,261 results.

8. EMBASE, MEDLINE, and PsycINFO (group* OR intervention* OR treatment* OR program* OR train* OR therap*).ti, 2,317,576 results.

9. EMBASE, MEDLINE, PsycINFO and 7 AND 8, 3537 results.

10. EMBASE, MEDLINE, PsycINFO and 6 AND 9, 312 results.

11. EMBASE, MEDLINE, PsycINFO and 10 (limit to: English language and publication year 1994-2014 and (age groups all adult 19 plus years or adolescent 13 to 18 years or young adult 19 to 24 years or adult 19 to 44 years or young adult and adult 19-24 and 19-44 or middle age 45 to 64 years or middle aged 45 plus years or all aged 65 and over or aged 80 and over)), 230 results. 


\section{Appendix 2-Summary of SST interventions}

Table 2 Summary of SST Interventions

\begin{tabular}{|c|c|c|c|c|}
\hline Study/studies & SST & Duration & Facilitators & Overview \\
\hline Ozonoff and Miller (1995) & $\begin{array}{l}\text { Social skills training } \\
\text { programme }\end{array}$ & $\begin{array}{l}90 \text { min, weekly } \\
\text { for } 14 \text { weeks }\end{array}$ & $\begin{array}{l}1 \text { leader and } 3 \text { helping } \\
\text { staff (no indication of } \\
\text { profession) }\end{array}$ & $\begin{array}{l}\text { First } 7 \text { weeks focusing on interactional and } \\
\text { conversational skills } \\
\text { Second } 7 \text { weeks focusing on ToM skills }\end{array}$ \\
\hline Hillier et al. $(2007,2011)$ & $\begin{array}{l}\text { Aspirations } \\
\text { programme }\end{array}$ & $\begin{array}{l}1 \mathrm{~h} \text {, weekly for } \\
8 \text { weeks }\end{array}$ & $\begin{array}{l}\text { Authors of study } \\
\text { (not clear of their } \\
\text { profession) }\end{array}$ & $\begin{array}{l}\text { Discussion based format } \\
\text { Developing social and vocational skills } \\
\text { Covered social communication, relationships, } \\
\text { independence and employment }\end{array}$ \\
\hline Tse et al. (2007) & $\begin{array}{l}\text { Social skills training } \\
\text { group }\end{array}$ & $\begin{array}{l}\text { 60-90 min, } \\
\text { weekly for } \\
12 \text { weeks }\end{array}$ & $\begin{array}{l}\text { A social worker and } \\
\text { a psychologist working } \\
\text { with adolescents in a } \\
\text { psychiatric setting }\end{array}$ & $\begin{array}{l}\text { Mixture of psychoeducation and experiential } \\
\text { exercises } \\
\text { Included role-play and didactic elements } \\
\text { Based on skillstreaming the adolescent } \\
\text { (Goldstein and McGinnis 2000) }\end{array}$ \\
\hline Turner-Brown et al. (2008) & SCIT-A & $\begin{array}{l}50 \text { min, weekly } \\
\text { for } 18 \text { weeks }\end{array}$ & Not stated & $\begin{array}{l}\text { Focuses on emotion training, figuring out } \\
\text { situations and integration }\end{array}$ \\
\hline $\begin{array}{l}\text { Laugeson et al. (2009), } \\
\text { Gantman et al. (2012), } \\
\text { Laugeson et al. (2012), } \\
\text { Mandelberg et al. (2014), } \\
\text { Schohl et al. (2014), } \\
\text { Yoo et al. (2014) }\end{array}$ & $\begin{array}{l}\text { PEERS (and Korean } \\
\text { version-Yoo et al. 2014) }\end{array}$ & $\begin{array}{l}90 \text { min, weekly } \\
\text { for } 12- \\
14 \text { weeks }\end{array}$ & $\begin{array}{l}\text { Recommends } 2 \text { clinical } \\
\text { psychologists, assisted } \\
\text { by at least } 2 \text { coaches } \\
\text { (psychology graduate } \\
\text { students) }\end{array}$ & $\begin{array}{l}\text { Focused on making friends, managing rejection } \\
\text { and resolving conflict } \\
\text { Parent assistance throughout adolescent intervention } \\
\text { Mixture of didactic elements, role-play and rehearsal } \\
\text { Parent's support weekly socialisation homework }\end{array}$ \\
\hline Mitchel et al. (2010) & $\begin{array}{l}\text { Group social skills } \\
\text { training }\end{array}$ & $\begin{array}{l}120 \text { min, weekly } \\
\text { for } 12 \text { weeks }\end{array}$ & $\begin{array}{l}\text { Members of the research } \\
\text { team (behaviour consultants) }\end{array}$ & $\begin{array}{l}\text { Curriculum adapted from 'Navigating the } \\
\text { Social World' (McAfee 2002) } \\
\text { Psychoeducation, modelling and role-play of } \\
\text { targeted social skills }\end{array}$ \\
\hline Liu et al. (2013) & $\begin{array}{l}\text { Workplace training } \\
\text { programme }\end{array}$ & $\begin{array}{l}6 \text { h a day, } 5 \text { days a } \\
\text { week for } \\
6 \text { months }\end{array}$ & $\begin{array}{l}2 \text { registered occupational } \\
\text { therapists and } 2 \text { rehabilitation } \\
\text { assistants }\end{array}$ & $\begin{array}{l}\text { Social, communication and emotion focus } \\
\text { Psychoeducation about workplace principles }\end{array}$ \\
\hline
\end{tabular}

Open Access This article is distributed under the terms of the Creative Commons Attribution 4.0 International License (http:// creativecommons.org/licenses/by/4.0/), which permits unrestricted use, distribution, and reproduction in any medium, provided you give appropriate credit to the original author(s) and the source, provide a link to the Creative Commons license, and indicate if changes were made.

\section{References}

Aman, M. G., Singh, N. N., Stewart, A. W., \& Field, C. J. (1985). The aberrant behaviour checklist: a behaviour rating scale for assessment of treatment effects. Journal of Mental Deficiency, 89, 485-491.

Aman, M. G., Tasse, M. J., Rojahn, J., \& Hammer, D. (1996). The Nisonger child behavioural rating form: a child behaviour rating form for children with developmental disabilities. Research in Developmental Disabilities, 17, 41-57. doi:10.1016/08914222(95)00039-9.

American Psychiatric Association. (2000). Diagnostic and Statistical Manual of Mental Disorders (4th ed., text rev.). Washington, DC: Author.

American Psychiatric Association. (2013). Diagnostic and Statistical Manual of Mental Disorder (5th ed.). Arlington: American Psychiatric Publishing.

Baron-Cohen, S. (1989). The autistic child's theory of mind: a case of specific developmental delay. Journal of Child Psychology and Psychiatry, 30, 285-297. doi:10.1111/j. 1469-7610.1989.tb00241.x.
Baron-Cohen, S., Leslie, A. M., \& Frith, U. (1985). Does the autistic child have a "theory of mind"? Cognition, 21, 37-46. doi:10.1016/00100277(85)90022-8.

Baron-Cohen, S., \& Wheelwright, S. (2004). The empathy quotient: an investigation of adults with Asperger syndrome or high functioning autism, and normal sex differences. Journal of Autism and Developmental Disorders, 34, 163-175. doi: 10.1023/B:JADD.0000022607.19833.00.

Baron-Cohen, S., Wheelwright, S., Skinner, R., Martin, J., \& Clubbley, E. (2001). The autism-spectrum quotient (AQ): evidence from Asperger syndrome/high functioning autism, males, females, scientists and mathematicians. Journal of Autism and Developmental Disorders, 32, 5-17. doi:10.1023/ A:1005653411471.

Beck, A. T., Steer, R. A., \& Brown, G. K. (1996). Beck depression inventory. San Antonio: The Psychological Corporation.

Bellini, S. (2004). Social skills deficits and anxiety in high-functioning adolescents with autism spectrum disorders. Focus on Autism and Other Developmental Disabilities, 21, 138-145. doi:10.1177/ 10883576040190020201.

Bellini, S. (2006). The development of social anxiety in adolescents with autism spectrumdisorders. Focus on Autism and Other Developmental Disabilities, 21, 138-145. doi:10.1177/ 10883576060210030201.

Blow, A. J., Sprenkle, D. H., \& Davis, S. D. (2007). Is who delivers the treatment more important than the treatment itself? Journal of Marital and Family Therapy, 33, 298-317. doi:10.1111/j.17520606.2007.00029.x.

Brownlow, C. (2010). Re-presenting autism: the construction of 'NT syndrome'. The Journal of Medical Humanities, 31, 243-255. doi:10.1007/s10912-010-9114-4. 
Cacioppo, J. T., \& Hawkley, L. C. (2009). Perceived social isolation and cognition. Trends in Cognitive Science, 13, 447.454. doi:10.1016/j. tocs.2009.06.005.

Chevallier, C., Kohls, G., Troiani, V., Brodkin, E. S., \& Schultz, R. T. (2012). The social motivation theory of autism. Trends in Cognitive Science, 16, 231-239. doi:10.1016/j.tics.2012.02.007.

Constantino, J. N. (2005). Social responsiveness scale. Los Angeles: Western Psychological Services.

Dapretto, M., Davies, M. S., Pfeifer, J. H., Scott, A. A., Sigman, M., Bookheimer, S. Y., \& Iacoboni, M. (2006). Understanding emotions in others: mirror neuron dysfunction in children with autism spectrum disorders. Nature Neuroscience, 9, 28-30. doi:10.1038/ nn1611.

Dawson, G., Toth, K., Abbott, R., Osterling, J., Munson, J., Estes, A., \& Liaw, J. (2004). Early social attention impairments in autism: social orienting, joint attention, and attention to distress. Developmental Psychology, 40, 271-283. doi:10.1037/0012-1649.40.2.271.

Department of Health. (2001). Valuing people - a new strategy for learning disability for the 21st century. London, Author.

Elliot, S. N., \& Gresham, F. M. (1987). Children's social skills: assessment and classification practices. Journal of Counseling and Development, 66, 96-99. doi:10.1177/002246698702100115.

Fisher, N., \& Happe, F. (2005). A training study of theory of mind and executive function in children with autistic spectrum disorders. Journal of Autism and Developmental Disorders, 35, 757-771. doi:10.1007/s10803-005-0022-9.

Gantman, A., Kapp, S. K., Orenski, K., \& Laugeson, E. A. (2012). Social skills training for young adults with high-functioning autism spectrum disorders: a randomised controlled pilot study. Journal of Autism and Developmental Disorders, 42, 1094-1103. doi:10. 1007/s10803-011-1350-6.

Goldstein, A. P., \& McGinnis, E. (2000). Skillstreaming the adolescent: new strategies and perspectives for teaching prosocial skills. Champaign: Research Press.

Gresham, F. M., \& Elliott, S. N. (1990). Social skills rating system. Circle Pines: American Guidance Service.

Hadjikhani, J. R. M., Snyder, J., \& Tager-Flusberg, H. (2006). Anatomical differences in the mirror neuron system and social cognition network in autism. Cerebral Cortex, 16, 1276-82. doi:10. 1093/cercor/bhj069.

Happé, F., \& Frith, U. (2006). The weak coherence account: detailfocused cognitive style in autism spectrum disorders. Journal of Autism and Developmental Disorders, 36, 5-25. doi:10.1007/ s10803-005-0039-0.

Harms, M. B., Martin, A., \& Wallace, G. L. (2010). Facial emotion recognition in autism spectrum disorders: a review of behavioral and neuroimaging studies. Neuropsychology Review, 20, 290-322. doi:10.1007/s11065-010-9138-6.

Hartup, W. W. (1989). Social relationships and their developmental significance. American Psychologist, 44, 120-126. doi:10.1037/0003066X.44.2.120

Heyes, C. (2010). Where do mirror neurons come from? Neuroscience and Biobehavioral Reviews, 34, 575-583. doi:10.1016/j.neubiorev. 2009.11.007.

Hillier, A., Fish, T., Cloppert, P., \& Beversdorf, D. Q. (2007). Outcomes of a social and vocational skills support group for adolescents and young adults on the autism spectrum. Focus on Autism and Other Developmental Disabilities, 22, 107-115. doi:10.1177/ 10883576070220020201.

Hillier, A. J., Fish, T., Siegel, J. H., \& Beversdorf, D. Q. (2011). Social and vocational skills training reduces self-reported anxiety and depression among young adults on the autism spectrum. Journal of Developmental and Physical Disabilities, 23, 267-276. doi:10. 1007/s10882-011-9226-4.
Laugeson, E. A., \& Frankel, F. (2006). Test of adolescent social skills knowledge. Available from UCLA Parenting and Children's Friendship Program, 300 Medical Plaza, Los Angeles.

Laugeson, E. A., Frankel, F., Mogil, C., \& Dillon, A. R. (2009). Parentassisted social skills training to improve friendships in teens with autism spectrum disorders. Journal of Autism and Developmental Disorders, 39, 596-606. doi:10.1007/s10803-008-0664-5.

Laugeson, E. A., Frankel, F., Gantman, A., Dillon, A. R., \& Mogil, C. (2012). Evidence-based social skills training for adolescents with autism spectrum disorders: the UCLA PEERS program. Journal of Autism and Developmental Disorders, 42, 1025-1036. doi:10.1007/ s10803-011-1139-1.

Leppänen, J. M., \& Nelson, C. A. (2006). The development and neural bases of facial emotion recognition. Advances in Child Development and Behavior, 34, 207-246. doi:10.1016/S0065-2407(06)80008-X.

Liberati, A., Altman, D. G., Tetzlaff, J., Mulrow, C., Gøtzsche, P. C., Ionnidis, J. P. A., \& Moher, D. (2009). The PRISMA statement for reporting systematic reviews and meta-analyses of studies that evaluate health care interventions: explanation and elaboration. Annals of Internal Medicine, 151, W65-94. doi:10.1371/journal.pmed. 1000100.

Liu, K. P. Y., Wong, D., Chung, A. C. Y., Kwok, N., Lam, M. K. Y., Yuen, C. M. C., \& Kwan, A. C. S. (2013). Effectiveness of a workplace training programme in improving social, communication and emotional skills for adults with autism and intellectual disability in Hong Kong - a pilot study. Occupational Therapy International, 20, 198204. doi:10.1002/oti.1356.

Lord, C., Rutter, M., DiLavore, P. C., \& Risi, S. (2008). Autism diagnostic observation schedule: manual. Los Angeles: Western Psychological Services.

Lugnegard, T., Hallerback, M. U., \& Gillberg, C. (2011). Psychiatric comorbidity in young adults with a clinical diagnosis of Asperger syndrome. Research in Developmental Disabilities, 32, 1910-1917. doi:10.1016/j.ridd.2011.03.025.

Mandelberg, J., Laugeson, E. A., Cunningham, T. D., Ellingsen, R., Bates, S., \& Frankel, F. (2014). Long-term treatment outcomes for parent-assisted social skills training for adolescents with autism spectrum disorders: the UCLA PEERS program. Journal of Mental Health Research in Intellectual Disabilities, 7, 45-73. doi: 10.1080/19315864.2012.730600.

McAfee, J. (2002). Navigating the social world: a curriculum for individuals with Asperger syndrome, high functioning autism and related disorders. Arlington: Future Horizons Inc.

Miller, A., Vernon, T., Wu, V., \& Russo, K. (2014). Social skill group interventions for adolescents with autism spectrum disorders: a systematic review. Review Journal of Autism and Developmental Disorders, 1, 254-265. doi:10.1007/s40489-014-0017-6.

Mitchel, K., Regehr, K., Reaume, J., \& Feldman, M. (2010). Group social skills training for adolescents with Asperger syndrome or high functioning autism. Journal of Developmental Disabilities, 16, 52-62.

Orsmond, G. I., Krauss, M. W., \& Seltzer, M. M. (2004). Peer relationships and social recreational activities among adolescents and adults with autism. Journal of Autism and Developmental Disorders, 34, 245-256. doi:10.1023/B:JADD.0000029547.96610.df.

Ozonoff, S., \& Miller, J. N. (1995). Teaching theory of mind: a new approach to social skills training for individuals with autism. Journal of Autism and Developmental Disorders, 25, 415-433.

Pelphrey, K. A., Sasson, N. J., Reznick, S., Paul, G., Goldman, B. D., \& Piven, J. (2002). Visual scanning of faces in autism. Journal of Autism and Developmental Disorders, 32(4), 249-261. doi:10. 1023/A:1016374617369.

Perkins, T., Stokes, M., McGillivray, J., \& Bittar, R. (2010). Mirror neuron dysfunction in autism spectrum disorders. Journal of Clinical Neuroscience, 17, 1239-1243. doi:10.1016/j.jocn.2010.01.026. 
Posavac, E. J., \& Carey, R. G. (1992). Program evaluation: methods and case studies (4th ed.). Englewood Cliffs: Prentice-Hall Inc.

Rao, P. A., Beidel, D. C., \& Murray, M. J. (2008). Social skills interventions for children with Asperger's syndrome or high-functioning autism: a review and recommendations. Journal of Autism and Developmental Disorders, 38, 353-361. doi:10.1007/s10803-0070402-4.

Reichow, B., \& Sabornie, E. J. (2009). Brief report: increasing verbal greeting initiations for a student with autism via a social story intervention. Journal of Autism and Developmental Disorders, 39, 1740-1743. doi:10.1007/s10803-009-0814-4.

Reichow, B., Steiner, A. M., \& Volume, F. (2012). Social skills groups for people aged 6 to 21 with autism spectrum disorders (ASD). The Cochrane Library, 7, 1-48. doi:10.1002/14651858.CD008511. pub2.

Russell, J. (1997). Autism as an executive disorder. New York: Oxford University Press.

Samson, A. C., \& Hegenloh, M. (2010). Stimulus characteristics affect humour processing in individuals with Asperger syndrome. Journal of Autism and Developmental Disorders, 40, 438-447. doi:10.1007/ s10803-009-0885-2.

Schohl, K. A., Van Hecke, A. V., Carson, A. M., Dolan, B., Karst, J., \& Stevens, S. (2014). A replication and extension of the PEERS intervention: examining effects on social skills and social anxiety in adolescents with autism spectrum disorders. Journal of Autism and Developmental Disorders, 44, 532-545. doi:10.1007/s10803-0131900-1.

Shtayermman, O. (2007). Peer victimization in adolescents and young adult diagnosed with Asperger's syndrome: a link to depressive symptomology, anxiety symptomolgy and suicidal ideation. Issues in Pediatric Nursing, 30, 87-107. doi:10.1080/ 01460860701525089.

Spielberger, C. D., Gorshuch, R. L., Lushene, P. R., Vagg, P. R., \& Jacobs, A. G. (1983). Manual for the state-trait anxiety inventory (form Y). Palo Alto: Mind Garden.

Sterling, L., Dawson, G., Estes, A., \& Greenson, J. (2008). Characteristics associated with presence of depressive symptoms in adults with autism spectrum disorder. Journal of Autism and Developmental Disorders, 38, 1011-1018. doi:10.1007/s10803007-0477-y.

Stewart, M. E., Barnard, L., Pearson, J., Hasan, R., \& O’Brien, G. (2006). Presentation of depression in autism and Asperger syndrome. Autism, 10, 103-116. doi:10.1177/1362361306062013.
Stokes, M., Newton, N., \& Kaur, A. (2007). Stalking, and social and romantic functioning among adolescents with autism spectrum disorder. Journal of Autism and Developmental Disorders, 37, 19691986. doi:10.1007/s10803-006-0344-2.

Sze, K. M., \& Wood, J. J. (2007). Cognitive behavioural treatment of comorbid anxiety and social difficulties in children with highfunctioning autism: a case study. Journal of Contemporary Psychotherapy, 37, 133-143. doi:10.1007/s10879-007-9048-y.

Tse, J., Strulovitch, J., Tagalakis, V., Meng, L., \& Fombonne, E. (2007). Social skills training for adolescents with Asperger syndrome and high-functioning autism. Journal of Autism and Developmental Disorders, 37, 1960-1968. doi:10.1007/s10803-006-0343-3.

Turner-Brown, L. M., Perry, T. D., Dichter, G. S., Bodfish, J. W., \& Penn, D. L. (2008). Brief report: feasibility of social cognition and interaction training for adults with high functioning autism. Journal of Autism and Developmental Disorders, 38, 1777-1784. doi:10.1007/ s10803-008-0545-y.

Vrticka, P., Black, J. M., \& Reiss, A. L. (2013). The neural basis of humour processing. Nature Reviews Neuroscience, 14, 860-868. doi:10.1038/nrn3566.

Wampold, B. E., \& Budge, S. L. (2012). The relationship - and its relationship to the common and specific factors of psychotherapy. The Counseling Psychologist, 40, 601-623. doi:10.1177/ 0011000011432709.

Weiss, M. J., \& Harris, S. L. (2001). Teaching social skills to people with autism. Behavior Modification, 25, 785-802. doi:10.1177/ 0145445501255007.

White, S. W., Ollendick, T., Albano, A. M., Oswald, D., Johnson, C., Southam-Gerow, M. A., \& Scahill, L. (2014). Randomized controlled trial: multimodal anxiety and social skills intervention for adolescents with autism spectrum disorder. Journal of Autism and Developmental Disorders, 43, 382-394. doi:10.1007/s10803-0121577-x.

Whitehouse, A. J., Durkin, K., Jaquet, E., \& Ziatas, K. (2009). Friendship, loneliness and depression in adolescents with Asperger's syndrome. Journal of Adolescence, 32, 309-322. doi: 10.1016/j.adolescence.2008.03.004.

Yoo, H.-J., Bahn, G., Cho, I.-H., Kim, E.-K., Kim, J.-H., Min, J.-W., \& Laugeson, E. A. (2014). A randomized controlled trial of the Korean version of the PEERS parent-assisted social skills training program for teens with ASD. Autism Research, 7, 145-161. doi:10.1002/aur.1354. 